\title{
Predictors of Hepatitis B Surface Antigen Titers two decades after vaccination in a cohort of students and post-graduates of the Medical School at the University of Palermo, Italy
}

\author{
Verso MG', Lo Cascio N², Noto Laddeca E³, Amodio E4, Stellino $S^{5}$, Currieri M $^{5}$, Giammanco G6, \\ Ferraro $D^{6}$, De Grazia ${ }^{6}$, Picciotto $D^{1}$ \\ ${ }^{1}$ Department of Sciences for Health Promotion and Mother-Child Care 'G. D'Alessandro', Occupational Health Section, \\ University of Palermo, via del Vespro 143, 90127 Palermo, Italy \\ ${ }^{2}$ Health Workers Medical Service - University Hospital Policlinico 'Paolo Giaccone', via del Vespro 143, 90127 Palermo, Italy \\ ${ }^{3}$ Unit of Occupational Health - University Hospital Policlinico 'Paolo Giaccone', via del Vespro 143, 90127 Palermo, Italy Italy \\ ${ }^{4}$ Epidemiology and Programming Service - Department of Planning, Purchasing and Control ATS Brianza, Monza, Italy \\ ${ }^{5}$ School of Specialization in Occupational Health, School of Medicine, University of Palermo, Italy \\ ${ }^{6}$ Department of Sciences for Health Promotion and Mother-Child Care 'G. D'Alessandro', Microbiology Section, University \\ of Palermo, via del Vespro 129, 90127 Palermo, Italy
}

Verso MG, Lo Cascio N, Noto Laddeca E, Amodio E, Stellino S, Currieri M, Giammanco G, Ferraro D, De Grazia S, Picciotto D. Predictors of Hepatitis B Surface Antigen Titers two decades after vaccination in a cohort of students and post-graduates of the Medical School at the University of Palermo, Italy. Ann Agric Environ Med. 2017; 24(2): 303-306. https://doi.org/10.26444/aaem/74716

\begin{abstract}
Introduction and objective. The introduction of a vaccine against hepatitis B virus (HBV) for newborn babies in Italy in 1991, extended to 12-year-old children for the first 12 years of application, has been a major achievement in terms of the prevention of HBV infection. The objective of this study was to analyse the long-term immunogenicity and effectiveness of HBV vaccination among healthcare students with different working seniorities.

Materials and method. A cross-sectional observational study of undergraduate and postgraduate students attending the Medical School of the University of Palermo was conducted from January 2014 - July 2016. HBV serum markers were performed with commercial chemiluminescence assays. Categorical variables were analyzed using the chi-square test (Mantel-Haenszel), whereas means were compared by using the Student's t test. Adjusted odds ratios (ORs) and 95\% confidence intervals (Cls) were also calculated by a multivariable logistic regression, using a model constructed to examine predictors of anti-HBs titer above $10 \mathrm{mIU} / \mathrm{mL}$, assumed as protective.

Results. Of the 2,114 subjects evaluated - all vaccinated at infancy or at the age of 12 years and were $\mathrm{HBsAg} / \mathrm{anti}-\mathrm{HBC}$ negative -806 (38.1\%) had an anti-HBs titre $<10 \mathrm{IU} / \mathrm{L}$. The latter were younger, more likely to be attending a healthcare profession school (i.e., nursing and midwifery), than a medical postgraduate level school, and more likely to have been vaccinated in infancy $(p<0.001,95 \% \mathrm{Cl} 2.63-5.26$, adjusted OR 3.70).

Conclusion. The results of the study suggest that assessment of HBV serum markers in workers potentially exposed to hospital infections is useful for identifying small numbers of unvaccinated subjects, or vaccinated subjects with low antibody titre, all of whom should be referred to a booster series of vaccinations.
\end{abstract}

Key words

HBV infection, HBV vaccination, Anti-HBs titre, Healthcare students, postgraduate medical students

\section{INTRODUCTION}

Hepatitis B infection has a variety of clinical course, including self-limited acute hepatitis, fulminant hepatic failure, chronic hepatitis, and progression to cirrhosis and hepatocellular carcinoma. HBV is transmitted by percutaneous or mucosal exposure to infected blood or other body fluids. In July 2016, the World Health Organization (WHO) estimated that 240 million people are chronically infected with $\mathrm{HBV}$, and more than 686,000 people die every year due to complications of hepatitis B, including cirrhosis and liver cancer [1]. The WHO's data reported that the hepatitis $\mathrm{B}$ prevalence is

Address for correspondence: Prof. Maria Gabriella Verso, Department of Sciences for Health Promotion and Mother-Child Care 'G. D'Alessandro', Occupational Health Section, University of Palermo, via del Vespro 143, 90127 Palermo, Italy Email: mariagabriella.verso@unipa.it

Received: 17 December 2017; accepted: 1 March 2017; first published on June 2017 highest in sub-Saharan Africa and East Asia, where between $5-10 \%$ of the adult population is chronically infected. High rates of chronic infections are also found in the Amazon and the southern parts of Eastern and Central Europe. In the Middle East and the Indian subcontinent, an estimated 2-5\% of the general population are chronically infected. Less than $1 \%$ of the population of Western Europe and North America is chronically infected [1].

Worldwide, two billion people are infected with HBV (1/3 of the world's population), and there are four million new cases of acute hepatitis per year, with almost 400 million chronic carriers [2].

In countries where large-scale vaccination efforts were made, the epidemiology of hepatitis B has been transformed. In Italy, the epidemiology of this infection changed after the introduction in 1991 of the vaccination of newborn babies that was extended to 12 -year-old children for the first 12 years of application. 
In Italy, from 1985-2014 in Italy, there has been a reduction in new notified cases: from 12 per 100,000 inhabitants to $<1$, as reported by the Integrated Epidemiological System for Acute Viral Hepatitis (SEIEVA) [2]. The Italian recommended adult/adolescent immunization schedule involves $\mathrm{HBV}$ vaccination doses at months 0,1 , and 6 , whereas infant vaccination starts from the third month of life for infants, with $2^{\text {nd }}$ and $3^{\text {rd }}$ doses at 5 and 11 months. The vaccine is $95 \%$ effective in preventing infection and the development of chronic disease and liver cancer due to hepatitis B. In Italy, $\mathrm{HBV}$ vaccination is also recommended for people at risk of acquiring $\mathrm{HBV}$ infection, including those with important occupational risk as health workers [3-5]. In Italy, according to the national laws, students are also considered as workers, and therefore, if they are exposed to physical, chemical, biological or psychological risks, they are evaluated by an occupational health physician.

Of the population undergoing to $\mathrm{HBV}$ vaccination, 95\% develop an effective immune response evaluated by the level of antibodies antiHBsAg $>10 \mathrm{mIU} / \mathrm{mL}$. Several studies confirm that the acquired immunity persists for at least 10 years after vaccination with level of antibodies $>10 \mathrm{mIU} / \mathrm{mL}$, but probably not longer, if vaccination had been performed at neonatal age [6-7]. In several countries in the world, students of faculties of medicine are examined to establish if the vaccination performed in infancy is still protective several decades after $\mathrm{HBV}$ vaccinations, because this is a population occupationallyexposed to a higher risk of acquiring HBV infection [8-20].

\section{OBJECTIVE}

The main aim of this study was to evaluate the persistence of long-term immunogenicity of HBV in students of the School of Medicine at the University of Palermo. A second aim was to identify possible predictive factors of long-term immunogenicity, such as age of individuals when they were vaccinated, gender and race.

\section{MATERIALS AND METHOD}

In this cross-sectional observational study, the levels of serum HBsAg, anti-HBs, and anti-HBc were evaluated of students attending schools of the health care professions, or postgraduate medical schools of the University of Palermo, Italy, who were examined for professional risks from January 2014 - July 2016. For each student, a standardized medical record was compiled, including socio-demographic (age, gender, country of origin) and clinical information (relatives' diseases and personal remote and proximate pathologies). A personal objective exam was additionally conducted for each subject before blood sampling.

Arbitrarily excluded from the study were subjects who met at least one of the following exclusion criteria: a) HBsAg personal or maternal positivity, chronic diseases or immunosuppression; b) absence of primary documentation of vaccination for $\mathrm{HBV}$; c) recent booster dose of $\mathrm{HBV}$ vaccine.

According to Italian law, the subjects were requested to provide written informed consent to the processing of data. Moreover, although it is not required in Italy for observational studies, approval of the Local Ethics Committee was aldso obtained [21].
Serological tests. Serological analyses were performed with commercial chemiluminescence assays (VITROS anti-HBs assay on the Vitros ECI Immunodiagnostic system, OrthoClinical Diagnostics, UK). In particular, the antibody to the hepatitis B surface antigen (anti-HBs) levels were expressed as $\mathrm{mIU} / \mathrm{mL}$. Dynamic range of quantification is $10-1000 \mathrm{mIU} / \mathrm{ml}$. The level of anti-HBs above $10 \mathrm{mIU} / \mathrm{mL}$ was considered as protective against HBV infection.

Statistical analysis. Statistical analysis was performed with $\mathrm{R}$ software version 3.3.2 (October 2016). The significance level chosen for all analyses was.05, 2-tailed. Absolute and relative frequencies were calculated for qualitative variables, whereas normally distributed quantitative variables were summarized as mean (standard deviation). Data normality was verified by the Shapiro-Wilk test for normality. Categorical variables were analyzed using the chi-square test (Mantel-Haenszel), means were compared by using the Student's t test. Adjusted odds ratios (ORs) and 95\% confidence intervals (CIs) were also calculated by a multivariable logistic regression model constructed to examine predictors of anti-HBs titer above $10 \mathrm{mIU} / \mathrm{mL}$ assumed as protective. All variables found to have a statistically significant association $(\mathrm{P}<.05)$ with anti$\mathrm{HBs}$ titer $>10 \mathrm{mIU} / \mathrm{mL}$ were entered in multivariate logistic regression model in order to check for independence. In the multivariate analysis, age was included as a continuous variable.

\section{RESULTS}

The main characteristics of the 2,114 subjects included in the study are shown in Table 1.

Table 1. General characteristics of subjects $(N=2,114)$ included in the study

\begin{tabular}{lc}
\hline & Total of students \\
\hline Total, $\mathrm{n}(\%)$ & $2,114(100)$ \\
\hline Sex, $\mathrm{n}(\%)$ & $1,275(60.3)$ \\
\hline - Males & $839(39.7)$ \\
\hline Age in years, mean \pm SD & $26.6 \pm 5.4$ \\
\hline Country of birth, $\mathrm{n}(\%)$ & $1(0.05)$ \\
\hline - Italy & $1(0.05)$ \\
\hline - Poland & $2,112(99.9)$ \\
\hline - Madagascar & $1,096(51.8)$ \\
\hline - Healthcare profession School & $1,018(48.2)$ \\
\hline
\end{tabular}

All enrolled subjects were vaccinated for HBV and HBsAg/ anti-HBc negative. 2, 870 (41.1\%) students received a course of 3 paediatric doses $(10 \mu \mathrm{g})$ of recombinant hepatitis B vaccine at their 3rd, 5th and 11th month of postnatal life, and 1,244 $(58.9 \%)$ received a course of 3 adult doses $(20 \mu \mathrm{g})$ of the same vaccine when they were 12 years old, as required by current law in Italy [22] The majority (61.9\%) of the students had an anti-HBs titre $>10 \mathrm{mIU} / \mathrm{mL}$ (Tab. 2).

Students with protective anti-HBs titre were statistically significantly older ( 27.9 vs. 24.4 years, $\mathrm{p}<0.001$ ), with fewer years after HBV vaccination (19.2 vs. 20.1, $\mathrm{p}<0.001)$, 
vaccinated at age 12 years $(76.0 \%$ with $\geq$ vs. $41.7 \%$ among vaccinate at infancy, $\mathrm{p}<0.001)$ and more frequently attending postgraduate medical school $(77.4 \%$ with $\geq$ vs. $47.4 \%$ among healthcare profession school, $\mathrm{p}<0.001)$. No statistically significant differences were observed in antibody titer between males and females.

Table 2. Variables associated with persistence of protective Hepatitis B surface antibody titers ( $\geq 10 \mathrm{mlU} / \mathrm{mL}$ )

\begin{tabular}{|c|c|c|c|}
\hline & \multicolumn{2}{|c|}{$\begin{array}{l}\text { Hepatitis B surface antibody } \\
\text { titers }\end{array}$} & \multirow[t]{2}{*}{$\mathrm{p}$-value } \\
\hline & $\geq 10 \mathrm{mlU} / \mathrm{mL}$ & $<10 \mathrm{mlU} / \mathrm{mL}$ & \\
\hline Total, n (\%) & $1,308(61.9)$ & $806(38.1)$ & - \\
\hline \multicolumn{4}{|l|}{ Sex, n (\%) } \\
\hline - Males & $513(61.1)$ & $326(37.6)$ & \multirow{2}{*}{0.58} \\
\hline - Females & $795(62.4)$ & $480(38.9)$ & \\
\hline Age in years, mean $\pm S D$ & $27.9 \pm 5.01$ & $24.4 \pm 5.47$ & $<0.001$ \\
\hline Years since HBV vaccination, mean $\pm S D$ & $19.2 \pm 3.57$ & $20.1 \pm 3.24$ & $<0.001$ \\
\hline \multicolumn{4}{|l|}{ Vaccination period, n (\%) } \\
\hline - Vaccinated at infancy & $363(41.7)$ & $507(58.3)$ & \multirow{2}{*}{$-<0.001$} \\
\hline - Vaccinated at age 12 years & $945(76.0)$ & $299(24.0)$ & \\
\hline \multicolumn{4}{|l|}{ University course, $\mathrm{n}(\%)$} \\
\hline - Healthcare profession school & $520(47.4)$ & $576(52.6)$ & \multirow{2}{*}{$<0.001$} \\
\hline - Postgraduate medical school & $788(77.4)$ & $230(22.6)$ & \\
\hline
\end{tabular}

The multivariable logistic regression model (Tab. 3) shows that after controlling for confounding, HBV vaccination at age of 12 years and attending postgraduate medical school, were significantly associated with increased odds of having protective Hepatitis B surface antibody titers $(\mathrm{OR}=3.70,95 \%$ $\mathrm{CI}=2.63-5.26$ and $\mathrm{OR}=1.40,95 \% \mathrm{CI}=1.02-1.94$, respectively). In particular, a protective anti-HBV titer was about 4 -fold more frequent among subjects vaccinated during adolescence than those vaccinated at infancy.

Table 3. Multivariable logistic regression model including variables statistically significantly associated with Hepatitis B surface antibody titers $\geq 10 \mathrm{mIU} / \mathrm{mL}$

\begin{tabular}{lcc}
\hline & Adjusted OR & $(95 \% \mathrm{Cl})$ \\
\hline Age in years & 0.81 & $(0.40-1.65)$ \\
\hline Years since HBV vaccination & 1.02 & $(0.99-1.05)$ \\
\hline Vaccination period & & \\
\hline$\quad$ - Vaccinated at infancy & referent & \\
\hline - Vaccinated at age 12 years & 3.70 & $(2.63-5.26)$ \\
\hline University course & & \\
\hline - Healthcare profession school & referent & \\
\hline - Postgraduate medical school & 1.40 & $(1.02-1.94)$ \\
\hline
\end{tabular}

\section{DISCUSSION AND CONCLUSIONS}

Health-care-related transmission has long been recognized as an important source of new HBV infections worldwide. It is estimated that in the United States, 12,000 health care workers were infected per year in the prevaccine era. A health care worker's risk of infection has been shown to correlate with level of blood and needle exposure [22].
It is internationally recognized that the healthcare profession and postgraduate medical students have a high occupational risk for HBV infection, also in countries with a low incidence of the disease $[10-11,14]$. In Italy, several studies have demonstrated a low endemic level (prevalence of HBsAg in the general population $<2 \%$ ) with an incidence of $\mathrm{HBV}$ infections of about 1 per 100,000 individuals, suggesting that healthcare workers and students could have a risk that is low but not negligible. Despite such evidence, for health professionals as well as for students and volunteers, to-date there is no obligation of vaccination, which is recommended only $[23,24]$. Fortunately a large majority of young Italian students have been vaccinated according to the national immunization programme that, since 1991, has included $\mathrm{HBV}$ vaccination as compulsory for infants and adolescents aged 12 years. Adolescent's vaccination was restricted to the first 12 years of the implementation of the vaccination law and, thus, in 2004, vaccination of 12-year-olds was stopped, but retained for infants.

As demonstrated by several studies, administration of $\mathrm{HBV}$ as part of a combination vaccine or as a monovalent vaccine induces long-lasting immune memory against $\mathrm{HBV}$ with long term antibody persistence. Several studies have reported that $85-90 \%$ of those vaccinated as adolescents have anti-HBs levels $>10 \mathrm{mIU} / \mathrm{mL}$ when measured 10 years after vaccination. This percentage was $40-60 \%$ for those vaccinated as infants, as measured 15-20 years after vaccination [25-26]. Both these data coincide with results obtained by the authors of the presented study, since more than $60 \%$ of their students had anti-HBV titers above $10 \mathrm{mUI} / \mathrm{mL}$, also more than 20 years after vaccination. Moreover, it should be pointed out that none of them received a booster dose after the primary vaccination programme, and in the primary documentation of vaccination for HBV no date was indicated for its administration. In the experience of the authors, they observed that this habit is also common among the general population.

Despite declining serum levels of antibody, international evidence shows that vaccine-induced immunity continues to prevent clinical disease or detectable viremic HBV infection. The long-term efficacy of $\mathrm{HBV}$ vaccination is confirmed when one considers that none of vaccinated subjects in the current study was found to be $\mathrm{HBsAg} / \mathrm{anti}-\mathrm{HBc}$ positive.

As already reported by several authors, including those of the presented study, a relatively high percentage of students (about $40 \%$ ) were revealed as having anti-HBV titers below $10 \mathrm{mIU} / \mathrm{mL}$.

The CDC recommend pre-exposure assessment of current or past anti-HBs results upon matriculation, followed by one or more additional doses of $\mathrm{HBV}$ vaccine for subjects with anti-HBs $<10 \mathrm{mIU} / \mathrm{mL}$, if necessary, helps to ensure HBV protection after contacts with blood or body fluids [27].

The administration of an HBV challenge dose after the primary schedule, induces strong anamnestic responses and is well tolerated [28]. In Italy, for Medical School students it is necessary to assess anti-HBs titre before making stages in hospital, in order to identify subjects with levels $<10 \mathrm{mIU} /$ $\mathrm{mL}$. In fact, although the current WHO view is that subjects with an anti-HBs titre $<10 \mathrm{mIU} / \mathrm{mL}$ still retain memory immunity, and no booster dose is necessary as part of a routine immunization programme, it could be beneficial to have a more protective approach for healthcare workers who are at significantly higher risk of exposure to HBV, administering a booster dose and rechecking titre after 1-2 
months to verify whether or not they are responders [29]. The screening in the healthcare cathegories is also fundamental to identify students and workers older than 35 years old, that have not been vaccinated, neither at birth or at 12 years of age, and immigrants from countries without universal immunization. This approach would allow identification of non-responders to the primary vaccination cycle or subjects with incomplete vaccination cycle.

Moreover we have found that two variables could help in predicting subjects at higher risk of having anti-HBs titre $<10$ $\mathrm{mIU} / \mathrm{mL}$. These variables are HBV vaccination at infancy and attending healthcare professional courses.

The possible causes of the low anti-HBs titres in adult subjects vaccinated in infancy could be due to the immaturity of the immune system in infants, at an age of life when there could be a lower interaction between $\mathrm{B}$ and $\mathrm{T}$ lymphocytes. Otherwise, it is less clear the reason for which students attending healthcare professional courses could have a higher risk of non-protective HBV titers', also after adjustment for confounding due to age, years after vaccination and vaccination period. Further analyses could be needed for answering to this intriguing question and some variables, as socio-demographic characterists could play a role in this association.

In this sense, the lack of more information about students (e.g. anti- HBV vaccine used for primary cycle, sociodemographic characteristics, immunological status, previous blood exposure etc) represents a major limit of the presented study. Despite these limitations, the presented study enriches the litterature on $\mathrm{HBV}$ vaccination, highlighting that although anti-HBV vaccination is associated with long persistence of protective titers, several students and post-graduates of the Medical School could benefit from a booster dose.

Moreover, some factors were found that could contribute to identify susceptible subjects and that could be associated with immune regulation pattern. Long-term follow-up studies several decades after vaccination administration will be needed to confirm the duration and persistence of immune memory.

\section{REFERENCES}

1. World Health Organization: Media Centre. Hepatitis B. Available online at: http://www.who.int/mediacentre/factsheets/fs204/en/

2. Tosti M.E. Istituto Superiore di Sanità - Centro Nazionale di Epidemiologia, Sorveglianza e Promozione della Salute (CNESPS): Principali risultati dei 30 anni di sorveglianza SEIEVA. Atti del XI Workshop SEIEVA. Il Sistema Epidemiologico Integrato dell'Epatite Virale Acuta (SEIEVA) a 30 anni dal suo avvio: riflessioni sullo stato dell'arte e prospettive future. Roma, 17 dicembre 2015. Available online at: http://www.iss.it/binary/seie2/cont/30anniSEIEVA.pdf

3. Piazza M, Da Villa G, Picciotto L, Abrescia N, Guadagnino V, Memoli $\mathrm{AM}$, et al. Mass vaccination against hepatitis B in infants in Italy. Lancet. 1988; 332: 1132.

4. Zanetti AR, Tanzi E, Romanò L, Grappasonni I. Vaccination against hepatitis B: the Italian strategy. Vaccine. 1993; 11: 521-4.

5. Romanò L, Paladini S, Tagliacarne C, Zappa A, Zanetti AR. The changing face of the epidemiology of type A, B, and D viral hepatitis in Italy, following the implementation of vaccination. Vaccine. 2009; 26: 3439-42.

6. Jan CF, Huang KC, Chien YC, Greydanus DE, Davies HD, Chiu TY, et al. Determination of immune memory to hepatitis B vaccination through early booster response in college students Hepatology. 2010; 51(5): 1547-54.

7. Hudu SA, Malik YA, Niazlin MT, Harmal NS, Adnan A, Alshrari AS, et al. Antibody and immune memory persistence post infant hepatitis B vaccination. Patient Prefer Adherence. 2013; 7: 981-6.

8. Noubiap JJ, Nansseu JR, Kengne KK, Tchokfe Ndoula S, Agyingi LA. Occupational exposure to blood, hepatitis B vaccine knowledge and uptake among medical students in Cameroon. BMC Med Educ. 2013; 13: 148.

9. Lohouès-Kouacou MJ, Assi C, Nigué L, Biékré AR, Ouattara A, Koné S, et al. Hepatitis B: cross-sectional study of knowledge and immunization among students at University of Cocody, Ivory Coast. Rev Epidemiol Sante Publique. 2013; 61(5): 494-8.

10. Riva MA, Madotto F, Conti S, Fornari C, Patronella G, Sormani M et al. Hepatitis B vaccination coverage and booster dose: results from a survey on healthcare students. G Ital Med Lav Ergon. 2012; 34 (3Suppl): 283-5.

11. Spradling PR, Williams RE, Xing J, Soyemi K, Towers J. Serologic testing for protection against hepatitis B virus infection among students at a health sciences university in the United States. Infect Control Hosp Epidemiol. 2012; 33(7): 732-6.

12. Carvalho P, Schinoni MI, Andrade J, Vasconcelos Rêgo MA, Marques $\mathrm{P}$, et al. Hepatitis B virus prevalence and vaccination response in health care workers and students at the Federal University of Bahia, Brazil. Ann Hepatol. 2012; 11(3): 330-7.

13. Lasemi E, Haddadpour N, Navi F, Rakhshan A, Rakhshan V. Rate of acquired immunity in dental students after hepatitis B vaccination. Dent Res J (Isfahan). 2011; 8(3): 128-31.

14. Bruno A, Borella-Venturini M, Giraldo M, Mongillo M, Zanetti E, Beggio M, et al. Prevalence of virus hepatitis B markers among medical students. G Ital Med Lav Ergon. 2007; 29(3Suppl): 752-4.

15. Lin CS, Zhu JY, Mai L, Lee WH, Gao ZL. Status of vaccination against hepatitis B among postgraduate students in medical higher education institutions in Guangzhou. Zhonghua Shi Yan He Lin Chuang Bing Du Xue Za Zhi. 2007; 21(2): 114-6.

16. Techasathit W, Ratanasuwan W, Sonjai A, Sangsiriwut K, Anekthananon T, Suwanagool S. Vaccination against hepatitis B virus: are Thai medical students sufficiently protected? J Med Assoc Thai. 2005; 88(3): 329-34.

17. Lamberti M, De Rosa A, Garzillo EM, Corvino AR, Sannolo N, De Pascalis S, et al. Vaccination against hepatitis b virus: are Italian medical students sufficiently protected after the public vaccination programme? J Occup Med Toxicol. 2015; 10:41.

18. Coppola N, Corvino AR, De Pascalis S, Signoriello G, Di Fiore E, Nienhaus A, et al. The long-term immunogenicity of recombinant hepatitis $B$ virus (HBV) vaccine: contribution of universal $\mathrm{HBV}$ vaccination in Italy. BMC Infect Dis. 2015; 25: 15-149.

19. Saffar H, Saffar MJ, Ajami A, Khalilian AR, Shams-Esfandabad K, Mirabi AM. Long-term T-cell-mediated immunologic memory to hepatitis B vaccine in young adults following neonatal vaccination. Hepat Mon. 2014; 14(9): e22223.

20. Zanetti AR, Mariano A, Romanò L, D囚amelio R, Chironna M, Coppola $\mathrm{RC}$, et al. Long-term immunogenicity of hepatitis B vaccination and policy for booster: an Italian multicentre study. Lancet. 2005; 366: 1379-1384.

21. Italian Medicines Agency: Linee guida per la classificazione e conduzione degli studi osservazionali sui farmaci. Gazzetta Ufficiale 2008, 76. 31/03/2008. Available online at: http://www.agenziafarmaco. gov.it/allegati/det_20marzo2008.pdf.

22. Colin W. Shepard, Edgar P. Simard, Lyn Finelli, Anthony E. Fiore, Beth P. Bell. Hepatitis B Virus Infection: Epidemiology and Vaccination. Epidemiologic Reviews; 2006, 28, 112-125.

23. Repubblica Italiana, Ministero della Salute: Circolare n. 19 del 30 novembre 2000 Protocollo per l'esecuzione della vaccinazione contro l'epatite virale B (D.M. 20 novembre 2000). Available online at: http:// www.salute.gov.it/imgs/C_17_normativa_1517_allegato.pdf

24. Repubblica Italiana, Ministero della Salute: Piano Nazionale Prevenzione Vaccinale (PNPV) 2012-2014. Available online at: http:// www.salute.gov.it/imgs/c_17_pubblicazioni_1721_allegato

25. Chiara F, Bartolucci GB, Mongillo M, Ferretto L, Nicolli A, Trevisan A. Hepatitis $B$ vaccination at three months of age: a successful strategy? Vaccine. 2013; 31(13): 1696-1700.

26. Stroffolini T, Guadagnino V, Caroleo B, De Sarro G, Focà A, Liberto $\mathrm{MC}$, et al. Long-term immunogenicity of hepatitis B vaccination in children and adolescents in a southern Italian town. Infection. 2012; 40(3): 299-302.

27. CDC. CDC guidance for evaluating health-care personnel for hepatitis $B$ virus protection and for administering postexposure management. MMWR 2013; 62(RR10): 1-19.

28. Avdicova M, Crasta PD, Hardt K, Kovac M: Lasting immune memory against hepatitis $\mathrm{B}$ following challenge $10-11$ years after primary vaccination with either three doses of hexavalent DTPa-HBV-IPV/ Hib or monovalent hepatitis B vaccine at 3,5 and 11-12 months of age. Vaccine. 2015; 33(23): 2727-33.

29. Publication WHO. Hepatitis B vaccines: WHO position paperrecommendations. Vaccine. 2010; 28: 589-590 Available online at: http://www.who.int/wer/2009/wer8440.pdf?ua=1 